\title{
Prevalence and antibiotic resistance pattern of Campylobacter species in foods of animal origin
}

\author{
Pallavi and Ashok Kumar \\ Division of Veterinary Public Health, Indian Veterinary Research Institute, Izatnagar, Bareilly, Uttar Pradesh, India. \\ Corresponding author: Pallavi, email: upadhyayapallavi.31@gmail.com, \\ AK: ashokakt@rediffmail.com
}

Received: 01-06-2014, Revised: 23-07-2014, Accepted: 31-07-2014, Published online: 13-09-2014

doi: 10.14202/vetworld.2014.681-684. How to cite this article: Pallavi, Kumar A (2014) Prevalence and antibiotic resistance pattern of Campylobacter species in foods of animal origin, Veterinary World 7(9): 681-684.

\begin{abstract}
Aim: The aim was to determine the prevalence and evaluation of antibiotic resistance pattern and minimum inhibitory concentration (MIC) of Campylobacter species isolated from foods of animal origin.

Materials and Methods: A total of 280 samples (comprising 150 chicken meat, 50 chevon and 80 milk) were collected from retail meat markets, slaughter houses and dairy farms and analyzed for isolation of Campylobacter species. A total of 29 isolates comprising 23 Campylobacter jejuni and 6 Campylobacter coli were recovered, characterized biochemically and confirmed by polymerase chain reaction. These isolates were then tested for antibiotic resistance pattern through disc diffusion method, and MIC was assessed by MIC strips. The antibiotic resistance assessment was performed against 8 antibiotics viz. ampicillin, co-trimoxazole, erythromycin, levofloxacin, gentamicin, ciprofloxacin, ceftriaxone, and norfloxacin.
\end{abstract}

Results: The prevalence of Campylobacter spp. in chicken meat, chevon and milk samples were observed $17.33 \%$, 6\% and $0 \%$, respectively. All the isolates were resistant to co-trimoxazole but sensitive to erythromycin. All the isolates showed different resistance pattern for the rest of the antibiotics. MIC results revealed that all the isolates were within prescribed concentrations for sensitivity for the antibiotics tested.

Conclusions: The foods of animal origin are source of Campylobacter infections to human beings. Thus, the development of antibiotic-resistant strains emphasizes the requirement of better surveillance and monitoring of the foods of animal origin and the use of antimicrobials in veterinary and human medicine require careful regulation.

Keywords: antibiotic resistance, Campylobacter, minimum inhibitory concentration, poultry.

\section{I ntroduction}

Thermophilic Campylobacter species, particularly Campylobacter jejuni and Campylobacter coli along with Salmonella species are well-recognized food-borne pathogens and recognized as most common agents of acute gastroenteritis in humans. Nowa-days, campylobacteriosis is a disease of great public health concern in underdeveloped, developing and developed countries especially industrialized ones [1].

The contaminated foods of animal origin, milk and water are the sources of infections of $C$. jejuni and $C$. coli for human beings [2-4]. Despite harboring these microorganisms, chickens rarely show signs of clinical disease and act as a source of infection for healthy animals and human beings [5]. The poultry products, especially the retail meat products have been frequently implicated as sources of infection [6-8]. Human campylobacteriosis is generally a clinically mild and self-limiting illness, but severe and systemic forms of the disease may require antimicrobial treatment, with macrolides and fluoroquinolones being the drugs of choice [9]. For the last few decades, increasing resistance to these antimicrobials has been

Copyright: The authors. This article is an open access article licensed under the terms of the Creative Commons Attributin License (http:// creative commons.org/licenses/by/2.0) which permits unrestricted use, distribution and reproduction in any medium, provided the work is properly cited. observed in Campylobacter isolates. The foods of animal origin are considered to be the transporters or vehicles of resistance isolates to human beings [10]. The reason for this is widespread use of antibiotics in animal feeds and further consumption of the foods of these animal origin lead to transfer of resistance isolates to humans.

The present study was performed in order to determine antibiotic resistance and minimum inhibitory concentration (MIC) in Campylobacter spp. isolated from foods of animal origin in Bareilly area of Uttar Pradesh, India.

\section{Materials and Methods}

\section{Collection of samples}

A total of 280 samples comprising of 150 poultry meat, 50 chevon and 80 milk samples were collected aseptically from retail meat markets, slaughterhouses and dairy farms in and around Bareilly area, Uttar Pradesh. The samples were immediately transported at $4^{\circ} \mathrm{C}$ to the laboratory and were processed within $4 \mathrm{~h}$ of collection to ensure that the organisms remain viable and cultivable.

\section{I solation}

The media and growth conditions for isolation of Campylobacter spp. as recommended by OIE Terrestrial Manual (2008) were used with necessary 
modifications [11]. Approximately, $25 \mathrm{~g}$ of the meat sample was enriched in $100 \mathrm{ml}$ Preston enrichment broth with Preston selective supplement and incubated at $42^{\circ} \mathrm{C}$ for $24-48 \mathrm{~h}$ under microaerobic conditions using CampyPak (BD, Oxoid) gas generating packs. In the case of milk, $50 \mathrm{ml}$ of each sample was centrifuged at 20,000 $\times g$ for $40 \mathrm{~min}$. The supernatant was discarded, and pellet was redissolved in $100 \mathrm{ml}$ of Preston enrichment broth and incubated under microaerobic conditions as mentioned above. Following enrichment, a loop full of inoculums was then streaked on modified charcoal cefoperazone deoxycholate agar (mCCDA) supplemented with CCDA supplement and plates were then incubated at $42^{\circ} \mathrm{C}$ for $24-48 \mathrm{~h}$ under microaerobic conditions. The suspected colonies exhibiting the typical characteristics (greyish, flat and moistened with a tendency to spread and with or without metal sheen) were picked up and subcultured again onto mCCDA to isolate pure colonies for further identification.

\section{Disc diffusion method}

The disc diffusion method for testing antibiotic resistance was performed as described by Bauer et al. (1966) [12]. The following antibiotic impregnated discs, supplied by Becton, Dickinson \& Co., USA, were used: Ampicillin (10 $\mu \mathrm{g})$, co-trimoxazole (25 $\mu \mathrm{g})$, erythromycin $(15 \mu \mathrm{g})$, levofloxacin $(5 \mu \mathrm{g})$, gentamicin $(10 \mu \mathrm{g})$, ciprofloxacin $(5 \mu \mathrm{g})$, ceftriaxone $(30 \mu \mathrm{g})$ and norfloxacin $(10 \mu \mathrm{g})$. Three to five isolated colonies of the same morphological type were selected and transferred into Mueller-Hinton broth and incubated at $37^{\circ} \mathrm{C}$ for $24 \mathrm{~h}$ under microaerobic conditions to obtain a turbidity of the inoculum equivalent to 0.5 standard McFarland. A sterile cotton swab was dipped into the suspension of each isolate and streaked across the entire surface of plates containing Mueller-Hinton agar with $5 \%$ sheep blood. The mentioned antibiotic discs were then placed on the plates and after 24-48 $\mathrm{h}$ of microaerobic incubation at $37^{\circ} \mathrm{C}$ the diameter of the inhibition zone around each disc was measured with callipers and recorded.

\section{C determination}

MIC for Campylobacter isolates was determined using HiComb MIC strips procured from Himedia Laboratories, India. The MIC was defined as the lowest concentration of the antimicrobial agent that completely inhibited the visible growth on the plates. The following antibiotic impregnated strips were used: Erythromycin (Strip A: 240-0.01 $\mu$ g and Strip B: 4-0.001 $\mu \mathrm{g}$ ), norfloxacin (Strip A: 240-0.01 $\mu \mathrm{g}$ and Strip B: 8-0.001 $\mu \mathrm{g}$ ), gentamicin (Strip A: 1024-8 $\mu \mathrm{g}$ and Strip B: 8.192-0.064 $\mu \mathrm{g}$ ), levofloxacin (Strip A: 240-0.01 $\mu \mathrm{g}$ and Strip B: 5-0.005 $\mu \mathrm{g}$ ) and ceftriaxone (Strip A: 256-2 $\mu$ g and Strip B: 2.048-0.016 $\mu$ g). The procedure as described for antibiotic resistance testing was followed for MIC determination. HiComb MIC strips were applied to blood-based Muller-Hinton plates with MIC scale facing upwards. Plates were incubated under microaerophilic atmosphere at $37^{\circ} \mathrm{C}$ for $48 \mathrm{~h}$. MIC value was determined as the value at which zone convene the comb-like projections of strips.

\section{Results}

A total of 29 Campylobacter isolates were recovered from 280 samples comprising 23 C. jejuni and 6 C. coli. The prevalence of Campylobacter spp. in chicken meat, chevon and milk samples were observed $17.33 \%, 6 \%$ and $0 \%$, respectively. None of the isolate was found resistant to erythromycin. Whereas, varying pattern of resistance was observed for other antibiotics viz. 26.67\%, 16.67\%, 6.67\%, 10\%, 3.33\% and $33.33 \%$ resistance was observed in the case of ciprofloxacin, ampicillin, levofloxacin, gentamicin, norfloxacin and ceftriaxone, respectively. All the isolates depicted $100 \%$ resistance against co-trimoxazole.

MICs of erythromycin sensitive isolates ranged between 0.01 and $0.1 \mu \mathrm{g} / \mathrm{ml}$. MIC level of $0.01 \mu \mathrm{g} / \mathrm{ml}$ was recorded in 10 isolates and $0.1 \mu \mathrm{g} / \mathrm{ml}$ in 19 isolates. MICs of norfloxacin sensitive isolates ranged between 0.1 and $1 \mu \mathrm{g} / \mathrm{ml}$. MIC level of $0.1 \mu \mathrm{g} / \mathrm{ml}, 0.5 \mu \mathrm{g} / \mathrm{ml}$ and $1 \mu \mathrm{g} / \mathrm{ml}$ were recorded in 10, 6 and 13 isolates, respectively. MICs of levofloxacin sensitive isolates ranged between 0.05 and $0.25 \mu \mathrm{g} / \mathrm{ml}$. MIC level of $0.05 \mu \mathrm{g} / \mathrm{ml}$ was recorded in 6 isolates, $0.1 \mu \mathrm{g} / \mathrm{ml}$ in 16 isolates and $0.25 \mu \mathrm{g} / \mathrm{ml}$ in 7 isolates. MICs of gentamicin sensitive isolates ranged between 0.064 and $8 \mu \mathrm{g} / \mathrm{ml}$. MIC level of $0.064 \mu \mathrm{g} / \mathrm{ml}, 0.128 \mu \mathrm{g} / \mathrm{ml}$ and $0.512 \mu \mathrm{g} / \mathrm{ml}$ were recorded in 18,7 and 4 isolates, respectively. MICs of ceftriaxone sensitive isolates ranged between 0.512 and $32 \mu \mathrm{g} / \mathrm{ml}$. MIC level of $4 \mu \mathrm{g} / \mathrm{ml}$ was recorded in 8 isolates, $8 \mu \mathrm{g} / \mathrm{ml}$ in 11 isolates, $16 \mu \mathrm{g} / \mathrm{ml}$ in 6 isolates and $32 \mu \mathrm{g} / \mathrm{ml}$ in 4 isolates. MIC results revealed that all the isolates were within prescribed concentrations for sensitivity for the antibiotics tested viz., erythromycin $(=0.5 \mu \mathrm{g} / \mathrm{ml})$, gentamicin $(=4 \mu \mathrm{g} / \mathrm{ml})$, levofloxacin $(=2 \mu \mathrm{g} / \mathrm{ml})$, norfloxacin $(=4 \mu \mathrm{g} / \mathrm{ml})$ except for ceftriaxone $(=8 \mu \mathrm{g} / \mathrm{ml})$ where 10 isolates revealed MIC value of more than $8 \mu \mathrm{g} / \mathrm{ml}$. The observations were in agreement to the results of antibiotic sensitivity test.

\section{Discussion}

Campylobacters are a normal inhabitant of the intestinal tract of animals and birds and are excreted in large numbers in feces. The fecal contamination of foods of animal origin occurs during unhygienic slaughtering practices. These campylobacters are further transferred to humans due to uncooked or partially cooked foods consumption.

The prevalence of Campylobacter spp. in chicken meat, chevon and milk samples were observed $17.33 \%, 6 \%$ and $0 \%$, respectively. Singh et al. [13] reported an overall occurrence rate of $12.7 \%$ from poultry meat and carcass collected from local poultry farms and retail markets of Bareilly. The isolation rate in chevon samples was found to be $6 \%$ in U.P. by 
Rajkumar et al. [14]. The observations of the previous studies carried out in same area are in concordance with the results of the present study. In this study, no Campylobacter isolate was recovered from raw milk samples and the findings are comparable to observations of Wegmuller et al. [15] and Singh et al. [16] who reported $0 \%$ isolation rate from raw milk samples.

Antimicrobial resistance in campylobacters isolated from foods of animal origin appears to be increasing in many countries. There is growing scientific evidence that the use of antibiotics in food animals leads to the development of resistant pathogenic bacteria that can reach humans through the food chain [17]. In the present study, most of the isolates were found to be sensitive to the fluoroquinolone class of antibiotics, the only exception being ciprofloxacin to which $26 \%$ of the isolates showed resistance. The similar findings for Campylobacter isolate from foods of animal origin were reported by Ge et al. [18]. The resistance to erythromycin and gentamicin was reported to be $0 \%$ and $10 \%$, respectively.

High degree of resistance was found to co-trimoxazole, an observation that supports the findings of Adekunle et al. [19]. Ampicillin resistance was seen in $16.6 \%$ of the isolates. Ewnetu and Mihret [20] have reported similar findings, where $17.5 \%$ of the isolates from foods of animal origin were found resistant to ampicillin. High degree of resistance was observed to ceftriaxone (33.33\%). Thus, erythromycin and gentamicin could be opted as drug of choice for treatment of campylobacteriosis when compared to other antimicrobials in this part of the world.

The determined MIC values for erythromycin, gentamicin and norfloxacin in our study were lower when compared to the findings of Jonkera and Picarda [21], whereas the values for ceftriaxone for some of the isolates were higher than the findings of Adekunle et al. [19]. The MIC values for levofloxacin observed in this study were in accordance to the findings of Rautelin et al. [22]. The highest MIC observed in the present study for erythromycin, gentamicin, levofloxacin, norfloxacin and ceftriaxone was $0.1 \mu \mathrm{g} / \mathrm{ml}, 0.512 \mu \mathrm{g} / \mathrm{ml}, 0.25 \mu \mathrm{g} / \mathrm{ml}, 1 \mu \mathrm{g} / \mathrm{ml}$ and $32 \mu \mathrm{g} / \mathrm{ml}$, respectively. The observations were in agreement to the results of antibiotic sensitivity test.

\section{Conclusion}

It is clearly concluded from the study that foods of animal origin are an important source of human campylobacteriosis. The presence of drug resistant strains among the isolates reveals that humans are at risk from a variety of sources with potential for severe health consequences. Therefore, the development of antibiotic-resistant strains emphasizes the requirement of better surveillance and monitoring of the foods of animal origin and the use of antimicrobials in veterinary and human medicine requires careful regulation.

\section{Authors' Contributions}

AK designed the research work and $P$ executed the research work in the laboratory. The authors were equally involved in the review of literature and manuscript preparation. Both authors read and approved the final manuscript.

\section{Acknowledgments}

Authors are thankful to Director, Indian Veterinary Research Institute for providing all the facilities to carry out the research work. Authors are also thankful to Indian Council of Agricultural Research for funding the research through 'Outreach Programme on Zoonotic Diseases'.

\section{Competing I nterests}

The authors declare that they have no competing interests.

\section{References}

1. Humphrey, T.S., O’Brien, S. and Madsen, M. (2007) Campylobacters as zoonotic pathogens: A food production perspective. Int. J. Food Microbiol., 117(3): 237-257.

2. Litrup, E., Torpdahl, M. and Nielsen, E.M. (2007) Multilocus sequence typing performed on Campylobacter coli isolates from humans, broilers, pigs and cattle originating in Denmark. J. Appl. Microbiol., 103(1): 210-218.

3. Kwan, P.S., Birtles, A. and Bolton, F.J. (2008) Longitudinal study of the molecular epidemiology of Campylobacter jejuni in cattle on dairy farms. Appl. Environ. Microbiol., 74(12): 3626-3633.

4. Huang, J.L., Xu, H.Y. and Bao, G.Y. (2009) Epidemiological surveillance of Campylobacter jejuni in chicken, dairy cattle and diarrhoea patients. Epidemiol. Infect., 137(8): $1111-1120$

5. Horrocks, S.M., Anderson, R.C., Nisbet, D.J. and Ricke, S.C. (2009). Incidence and ecology of Campylobacter jejuni and Campylobacter coli in animals. Anaerobe, 15(1-2): 18-25.

6. Zhao, C., Ge, B., and Villena, J. (2001) Prevalence of Campylobacter spp., Escherichia coli, and Salmonella serovars in retail chicken, turkey, pork, and beef from the Greater Washington, D.C. area. Appl. Environ. Microbiol., 67(12): 5431-5436.

7. Ge, B., White, D.G. and McDermott, P.F. (2003) Antimicrobial-resistant Campylobacter species from retail raw meats. Appl. Environ. Microbiol., 69(5): 3005-3007.

8. Meldrum, R.J. and Wilson, I.G. (2007) Salmonella and Campylobacter in United Kingdom retail raw chicken in 2005. J. Food Prot., 70(8): 1937-1939.

9. Moore, J.E., Barton, M.D., Blair, I.S., Corcoran, D., Dooley, J.S.G., Fanning, S., Kempf, I., Lastovica, A.J., Lowery, C.J., Matsuda, M., McDowell, D.A., McMahon, A., Millar, B.C., Rao, J.R., Rooney, P.J., Seal, B.S., Snelling, W.J., and Tolba, O. (2006) The epidemiology of antibiotic resistance in Campylobacter spp. Microbes Infect., 8: 1955-1966.

10. Luangtongkum, T., Jeon, B., Han, J., Plummer, P., Logue, C.M., and Zhang, Q. (2009) Antibiotic resistance in Campylobacter: Emergence, transmission and persistence. Future Microbiol., 4(2): 189-200.

11. Campylobacter jejuni and Campylobacter coli. (2008) OIE Terrestrial Manual. Chapter 2.9.3. p 1185-1191.

12. Bauer, A.W., Kirby, W.M. and Sherris, J.C. (1966) Antibiotic susceptibility testing by a standardized single disk method. Am. J. Clin. Pathol., 45(4): 493-496.

13. Singh, R., Singh, P.P., Rathore, R.S., Dhama, K. and Malik, S.V.S. (2009) Prevalence of Campylobacter jejuni 
and Campylobacter coli in chicken meat and carcasses collected from local poultry farms and retail shops of Bareilly, Uttar Pradesh, India. Indian. J. Comp. Microbiol. Immunol. Infect. Dis., 30: 90-93.

14. Rajkumar, R.S., Yadav, A.S., Rathore, R.S., Mohan, H.V. and Singh, R.P. (2010) Prevalence of Campylobacter jejuni and Campylobacter coli from unorganized and organized small scale poultry dressing units of Northern India. $J$. Vet. Public. Health., 8: 1-5.

15. Wegmuller, B., Luthy, J., and Candrian, U. (1993) Direct polymerase chain reaction detection of Campylobacter jejuni and Campylobacter coli in raw milk and dairy products. Appl. Environ. Microbiol., 59(7): 2161-2165.

16. Singh, H., Rathore, R.S., Singh, S. and Cheema, P.S. (2011) Comparative analysis of cultural isolation and PCR based assay for detection of Campylobacter jejuni in food and faecal samples. Braz. J. Microbiol., 42: 181-186.

17. Looveren van, M., Georges, D., Zutter De, L., Doumont, J.M., Lammens, C., Wijdooghe, M., Vandamme, P., Jouret, M., Cornelis, M. and Goosens, H. (2001) Antimicrobial susceptibilities of Campylobacter strains isolated from food animals in Belgium. J. Antimicrob. Chemother., 48(2): 235-240.
18. Ge, B., Bodeis, S., Walker, R.D., White, D.G., Zhao, S., McDermott, P.F. and Meng, J. (2002) Comparison of the E test and agar dilution for in vitro antimicrobial susceptibility testing of Campylobacter. J. Antimicrob. Chemother., 50(4): 487-494.

19. Adekunle, O.C., Coker, A.O. and Kolawole, D.O. (2009) Antibiotic susceptibility pattern of strains of Campylobacter coli isolated in Osogbo, Nigeria. Biol. Med., 1: 20-23.

20. Ewnetu, D. and Mihret, A. (2010) Prevalence and antimicrobial resistance of Campylobacter isolates from humans and chickens in Bahir Dar, Ethiopia. Foodborne Pathog. Dis., 7(6): 667-670.

21. Jonkera, A. and Picarda, J.A. (2010) Antimicrobial susceptibility in thermophilic Campylobacter species isolated from pigs and chickens in South Africa. Tydskr. S. Afr. Vet. Ver., 81(4): 228-236.

22. Rautelin, H., Vierikko, A., Hanninen, M.L. and Vaara, M. (2003) Antimicrobial susceptibilities of Campylobacter strains isolated from Finnish subjects infected domestically or from those infected abroad. Antimicrob. Agents Chemother., 47: 102-105.

\section{$* * * * * * * *$}

